\title{
Local, Global and Virtual Buzz: the Importance of Face-to-face Contact in Economic Interaction and Possibilities to Go Beyond
}

\author{
Harald Bathelt \& Philip Turi
}

\author{
Version Post-print/accepted manuscript \\ Citation Bathelt, H., \& Turi, P. (2011). Local, global and virtual buzz: The \\ (published version) importance of face-to-face contact in economic interaction and \\ possibilities to go beyond. Geoforum, 42(5), 520-529. \\ Copyright / License \\ (C) 2011. This manuscript version is made available under the CC-BY- \\ NC-ND 4.0 license. \\ http://creativecommons.org/licenses/by-nc-nd/4.0/ \\ Publisher's Statement The version of record [Bathelt, H., \& Turi, P. (2011). Local, global and \\ virtual buzz: The importance of face-to-face contact in economic \\ interaction and possibilities to go beyond. Geoforum, 42(5), 520-529.] is \\ available online at: \\ http://www.sciencedirect.com/science/article/pii/S0016718511000558 \\ [doi:10.1016/j.geoforum.2011.04.007]
}

How to cite TSpace items

Always cite the published version, so the author(s) will receive recognition through services that track citation counts, e.g. Scopus. If you need to cite the page number of the TSpace version (original manuscript or accepted manuscript) because you cannot access the published version, then cite the TSpace version in addition to the published version using the permanent URI (handle) found on the record page. 


\title{
Local, global and virtual buzz: the importance of face- to-face contact in economic interaction and possibilities to go beyond
}

\author{
Harald Bathelt* \\ University of Toronto, Department of Political Science and Department of Geography \& \\ Program in Planning, Sidney Smith Hall, 100 St. George Street, Toronto ON M5S 3G3, Canada, \\ URL: http://www.harald-bathelt.com, E-mail: harald.bathelt@utoronto.ca \\ and \\ Philip Turi \\ University of Western Ontario, Faculty of Law, \\ Josephine Spencer Niblett Law Bldg, 1151 Richmond Street, London ON LB 243, Canada, \\ E-mail:pturi@uwo.ca
}

To be re-submitted to

Geoforum

* Corresponding author 


\title{
Local, global and virtual buzz: the importance of face-to-face contact in economic interaction and possibilities to go beyond
}

\begin{abstract}
Novel information and communication technologies have created new possibilities for transferring information and knowledge over distance. Although this might open up broad options for economic interaction, knowledge regarding the effects of these changes on the geographies of production and innovation is still incomplete. Under these circumstances, permanent co-location and face-to-face (F2F) interaction may be efficient in some contexts but not in others. Support by computer-mediated communication (CMC), temporary, and virtual interaction is increasingly becoming the basis for establishing trans-local production networks. By combining results from social psychology with economic geography, it is argued that there is no generally superior spatial fix for economic interaction. Different spatial configurations can be advantageous in different production and innovation contexts, even over large distances without permanent or even regular F2F contact. This paper systematically investigates the effects of new communication technologies and different organisational forms for economic interaction by emphasizing the potential of combining $\mathrm{CMC}$ with forms of temporary and permanent $\mathrm{F} 2 \mathrm{~F}$ interaction.
\end{abstract}

Keywords: Computer-mediated communication (CMC), economic interaction, face-toface (F2F) contact, global buzz, local buzz, virtual buzz

JEL classifications: D83, F59, M39, O33, Z13 


\section{Introduction}

In an age marked by radical innovations in information and communication technologies, new possibilities exist to transfer information and knowledge over distance. Although such possibilities offer new options for economic interaction, our understanding regarding their effects on geographies of production, distribution, and innovation is still limited. From a firm perspective, we still have limited knowledge about which economic activities are more efficiently and profitably carried out locally - involving permanent co-presence - and which other activities can be carried out over distance through, for instance, corporate networks and/or communities of practice. Even though we are far from being able to provide a definite categorisation in this paper, we wish to argue that processes of knowledge generation can and do involve different geographies of organisation and interaction (Amin and Roberts 2008). Indeed, while a growing body of literature emphasizes the potential of new technologies to change communication patterns and the nature of knowledge generation (e.g. Leamer and Storper 2001; Moriset and Malecki 2009), others view their impact as circular. Leamer and Storper (2001) predict that the Internet will likely support both deagglomeration and, at the same time, agglomeration tendencies of economic activities. We use this as a starting point for our analysis in which we aim to systematically investigate the effects of new communication technologies and different organisational forms on economic interaction and knowledge generation. Our emphasis centres 
on the potential effects of combining computer-mediated communication (CMC) with temporary and permanent forms of face-to-face (F2F) interaction. ${ }^{1}$

In doing so, we question the assumed priority of local over non-local interaction that was, in the past, characteristic of much of the literature on clusters, industrial districts, and regional innovation systems. As Oinas (1999) clearly recognises, there is little empirical evidence to support broad claims of a supposed predominance of proximate over distant relations in economic interaction. In fact, as argued by others (Amin 2004; Bathelt 2006), the local cannot be seen in isolation from other spatial levels as local knowledge and competencies are continuously enriched, fed, and challenged by trans-local linkages. Such work suggests that the local and global spheres are inseparably interwoven. We argue in this paper that permanent co-location and F2F interaction may be efficient in some economic contexts but not in others (Gertler and Levitte 2005). Business leaders located in one region, for example, simply may not like one another or have rather different goals, thus hampering opportunities for regional interaction. Conversely, interaction in global production networks has become quite widespread, and even small and medium-sized firms engage in organisational configurations which span across geographic boundaries, cultures, and nation-states. In short, different settings can be structured in a way so as

${ }^{1}$ We use the term "computer-mediated communication" throughout this paper to refer to any type of communication supported by and facilitated through networked computers. Although sometimes being primarily related to text-based interaction (Gibson and Cohen 2003; Wainfan and Davis 2004), we also include communication involving audio- or video-based exchanges. The nature of such communication has drastically changed over time from simple text-based messages in the 1980s and 1990s to elaborate video-conferencing and other web-based collaborative tools in the 2010s. While technological progress has certainly enhanced possibilities for virtual interaction and knowledge creation by imitating the nature of F2F encounters, it has also reintroduced possible limitations associated with F2F interaction, as discussed later on. Our intention is to identify the potential of such virtual knowledge exchanges, rather than to give a comprehensive overview of all variations. 
to enable efficient economic interaction - even over very large distances. However, we need to discuss under which conditions and in which industries such interaction can easily be organised, and in which other settings it is less likely.

In the context of this debate, this paper will systematically investigate the role and importance of F2F interaction and provide examples of how and for which activities different geographies come into play in communication and knowledge generation. Rather than emphasizing advantages of proximity per se, we argue that it is important to analyse the preconditions, characteristics, and outcomes incurred through F2F and other interaction in different spatial settings. It is suggested that new communication media combined with specific settings for interaction can mitigate, and even overcome, the need for permanent co-location. However, this might not always be feasible. In order to more fully develop this argument, we move beyond geographic literature and integrate studies from the field of social psychology. Such studies, which have been widely neglected in economic geography and regional economics (Thrift 2004), shed new light on how F2F interaction operates, and how CMC and virtual interaction can make up for some of the problems arising during remote collaboration. Although sociologists have also analysed the role of F2F communication and the influence of the Internet on social interaction, experiments conducted by social psychologists are particularly well-suited to an inquiry into the potentialities of non-F2F based virtual interaction, and its spatial consequences. $^{2}$

${ }^{2}$ Sociological analyses focussing on the role of the Internet on actual social relations and communication patterns have found that existing institutions stabilise prior communication patterns rather then changing them abruptly. Recent studies of e-mail communication emphasize, for instance, that new technologies neither have a major impact on the frequency of F2F contacts, nor on the distance of social relations (Mok, Wellman and Basu 2007; Carrasco, Wellman and Miller 2008; Mok, Wellman and Carrasco 2010). As such studies investigate interaction 
The goal of this paper is to move beyond a simple dichotomy of local versus global spheres and, instead, inform a broader discussion concerning the potentialities for economic interaction in settings not characterised by permanent co-location of the agents involved. In integrating findings from social psychology and economic geography, we provide a new angle toward more differentiated perspectives of connectivities between and the permeability of different spatial scales (Gertler and Levitte 2005; Faulconbridge 2006; Jones 2007; Amin and Robins 2008), leading to trans-scalar configurations of economic activities. An important contribution of this analysis is thus to explore and link different streams of the literature on the role of F2F interaction in economic context which have remained rather separate thus far.

The following analysis will begin by highlighting important findings from the literature about the role of F2F interaction, its components, and advantages. Section three emphasizes the advantages of permanent co-location and regular F2F contact in clusters creating what we refer to as "local buzz". The limitations of interaction in proximate relations will also be pointed out as they may lead to negative lock-in processes. Section four argues that permanent co-location should be viewed as an exception rather than a rule in complex production chains which can have a global reach. Section five engages in a discussion of the characteristics and effects of CMC and related virtual interaction. Thereafter, section six argues that interaction across locations can sometimes open new potentialities in innovation, not likely available to permanent F2F encounters within groups and corporations. Finally, section seven will draw conclusions and argue that the combination of different forms of permanent and temporary F2F-based and virtual

under the influence of pre-existing institutions, their ability to evaluate the potential of new technologies to shift spatial communication patterns is limited. 
interaction will generate new opportunities for integrating production and innovation processes at the global scale.

\section{Role of proximity and face-to-face (F2F) interaction}

While information and communication technologies have provided new and unprecedented opportunities for knowledge transfer over distance, a large body of literature continues to stress the benefits stemming from geographic proximity between economic agents. Studies in economic geography have made a concerted effort to advance the importance of "being there" (e.g. Gertler 1995, Morgan 2004), with respect to stimulating "local buzz" and transferring and implementing new technologies (Bathelt, Malmberg and Maskell 2004). A broad literature has emphasized the role of cost factors related to transportation and transaction costs (Scott 1988), but, in highlighting the role of untraded interdependencies (Storper 1997), has not provided much insight to what exactly the advantages of F2F interaction are (Jones 2007).

Social psychologists have similarly examined remote and proximate collaboration, especially since the advent of modern information and communication technologies. In examining the efficiency of CMC on group processes and outcomes, this research has lent special attention to the social and cognitive factors arising during F2F interaction. It emphasizes how integrational and informational aspects of F2F interaction afford the transfer of complex messages and the stimulation of trust under conditions of uncertainty. These studies provide a deeper understanding of the processes underlying "being there".

In their foundational analysis on the social psychology of telecommunications, Short, Williams and Christie (1976) have identified a range of non-verbal cues such as facial expression, direction of gaze, posture, and physical distance, arising during F2F interaction (see, also, Goffman 1969). They distinguish two types of functions played by these non-verbal cues that 
accrue subconsciously between interacting agents through F2F communication. Short, Williams and Christie (1976) gleaned such observations through conducting a series of controlled experiments where study participants were asked to perform various tasks, such as negotiation, using telephones, as well as F2F media. Although these findings were not drawn from purely economic interaction, we believe they can be used to inform other contexts, such as an analysis of product properties between producers and users (Gertler 2004) or reflexive discussions of research problems in complex technologies (Storper 1997). The first function of F2F interaction that is emphasized in the social psychology literature concerns the passage of information from one individual to another; while the second is concerned with the integrational aspects of the communication process (Birdwhistell 1970).

(i) Informational functions. The first of three informational functions mentioned here is illustration. Short, Williams and Christie (1976) refer to hand gestures that accompany speech used to illustrate an action, object, or direction for emphasis. The redundancy introduced by such gestures improves the clarity of a message. The second informational function refers to emblematic gestures that are used instead of words; for instance, a head shake signifying "no". While such cues are easily substitutable by words, they are nonetheless active during F2F encounters and serve to augment fluidity in a conversation. In economic contexts, for example, they actively support search processes for solutions. Third, non-verbal cues may be utilised by the listener to key in on the speaker's attitude and intentions, something that is helpful, for instance, in evaluating new trends presented at trade fairs (Bathelt and Schuldt 2008). Facial expression, gesture, and similar cues can indicate changes in a relationship, such as the shift from a more relaxed to a more formal posture - a potentially important cue in negotiations of prices. Similarly, information is conveyed through F2F communication about the speaker's affective reaction (i.e. pride, uncertainty) to what may be otherwise an emotion-free statement. 
(ii) Integrational functions. Of three major integrational functions described by Short, Williams and Christie (1976), the first refers to mutual attention and responsiveness. During conversations between two actor groups, there exists a continuous stream of evidence that both parties are attending and responding. This is achieved primarily by eye-gaze, head nods, and gestures. However, mutual attention can also arise from brief verbal utterances such as "yes" and "no". The second function is control channel. Here, cues such as head nods and eye movements are used to determine who shall speak and for how long. As agents are not usually aware of making or receiving these signals, they are affected by the removal of visual cues. This could provide a problem, for instance in discussing failure in production processes, if this interaction occurs over distance without F2F contact. Finally, the third function is feedback. In order to plan his or her utterances, a speaker needs to know how others are reacting to what has been said before. Non-verbal signals track agreement or disagreement and other moment-to-moment changes in the conversation. In this respect, a critical property of non-verbal signalling is that it occurs simultaneously with verbal communication, without interrupting it in the process (see, also, Storper and Venables 2004). If the visual channel is removed, a speaker must wait for a verbal reply from the other party before he or she gets feedback on his or her remarks. For example, people might refrain from certain topics or switch to other topics when lacking feedbacks, as misunderstanding becomes more likely. Additionally, speakers normally adapt the ongoing message to responses of the recipients. The removal of this feedback could impair the efficiency of adapting the message by the listener. Such integrational feedback is key in technological research in corporate or inter-firm networks where preliminary settings are tested, and the next set of fixes is then discussed (Storper 1997). However, such cues are equally important also in lowtechnology segments when, for instance, exchanging experiences of entering a new market via Brownfield or Greenfield investment (Glückler 2006). For similar reasons, professional service 
firms follow their clients in international locations to be able to maintain F2F consultation services (Faulconbridge 2006). From this, one might expect that tasks in which the behaviour of one individual is highly contingent on the moment-to-moment affective reactions of others, as in problem-solving or brainstorming scenarios, would be particularly sensitive to variation in the communication medium.

While these integrational and informational aspects of F2F encounters enable the transfer of complex messages, collectively they serve to reduce uncertainties between communicators and, in turn, engender trust. The latter point is particularly important in unknown or volatile economic contexts (Leamer and Storper 2001), such as a firm's entry into a new market characterised by different institutional-cultural settings implying different types of behaviour (Depner 2006). Numerous studies in social psychology have also shown that cooperative work environments and successful business transactions require the development of trust (Fukuyama 1995; Nelson and Cooprider 1996; Jøsang 1996; Swagerman, Dogger and Maatman 2000). Geographical proximity acts as a factor of cohesion by supporting long-lasting co-operative behaviour thanks to the repetition of commitment. As will be discussed in the next section, this is prominent in successful clusters which exist based on permanent co-presence and F2F interaction between agents. In contrast, distant agents have fewer opportunities for the kinds of interaction that maintain and develop emotional trust.

With access to the integrational and informational factors underlying F2F communication, interacting agents are provided with greater assurance about each other and the meanings behind their messages and evaluations (Olsen and Olsen 2003). In a reflexive manner, greater clarity serves to support closer social relations and strengthens the extent to which the agents trust each other (Granovetter 1985). Furthermore, F2F interaction creates opportunities for controlling the performance of other agents, for instance in small-workplace contexts (Crang 1994), and can thus 
be a mechanism for managers to exercise power over subordinate workers, or for large firms to control small suppliers in the same region (Allen 1997; Taylor 2000). In contrast, the absence of a visual channel reduces the possibilities for an accurate expression of the socio-emotional context and decreases the information available about the self-images, attitudes, moods, and reactions of others. This allows for deviating and opportunistic behaviour. As a consequence, communicative activities important to the innovation process - such as the articulation of thoughts or ideas, accommodation, negotiation, and persuasion - are highly subject to influences by the medium of communication. The benefits and shortcomings of mediums other than F2F interaction, in part, hinge upon their ability to allow for the actualisation and transfer of non-verbal cues.

As will be discussed in the next sections, different configurations of economic interaction and knowledge creation involve different mixtures of co-location, F2F meetings, and virtual communication. We will demonstrate how these settings allow agents to benefit from F2F interaction and how ongoing interaction supports the creation of particular information and communication ecologies.

\section{Permanent co-presence in clusters and local buzz}

Much research in economic geography has been led by the assumption that spatial proximity is key to understanding economic interaction because it "is still a fundamental way to bring people and firms together, to share knowledge and to solve problems" (Storper and Walker 1989: 80). There is significant empirical evidence which supports this view (see, also, Morgan 2004). In the context of urban or regional agglomerations, or clusters (Porter 1990; 2003; Gordon and McCann 2000; Enright 2003; Preissl and Solimene 2003), recent research has linked the importance of proximate relations to the thick web of information and knowledge connecting local agents and circulating between them (Hendry, Brown and DeFillippi 2000; Pinch, Henry, 
Jenkins and Tallmann 2003). The general importance of thick local/regional information and knowledge ecologies has been identified in many studies in different technological, economic, and cultural contexts, albeit little work exists that compares these different settings in a systematic way. This includes studies about the rise of high-technology clusters such as Silicon Valley (Scott 1988; Saxenian 1994), the constant reconfiguration of small-firm networks in traditional industries such as textile, shoe, or leather production in the Third Italy (Scott 1988; Asheim 2000), or producer-user interaction in high-end knowledge-based producer services (Scott 1988; Pinch, Henry, Jenkins and Tallmann 2003). The resulting knowledge flows establish a rich information and communication ecology referred to as "noise" (Grabher 2002) or "buzz" (Storper and Venables 2004). This local buzz consists of specific information flows, knowledge transfers, and continuous updates, as well as opportunities for learning in organised and spontaneous meetings (Storper and Venables 2004; Bathelt, Malmberg and Maskell 2004). The importance and quality of a cluster's buzz is related to a number of features. Three such features are listed below which are partly overlapping and make such a setting especially valuable for processes of learning and knowledge creation (Bathelt 2007):

First, the co-presence of many specialised firms of a particular value chain and regular F2F contacts between specialists from these firms generate a specific milieu for the exchange of experiences, information, and knowledge within a cluster. In this milieu, F2F encounters and the associated non-verbal cues generate informational and integrational advantages in communication enabling efficient knowledge exchange and circulation. This leads to stronger local embeddedness of firms, supporting fine-grained information flows and interactive learning (Granovetter 1985; Uzzi 1997). Specific information about technologies, markets, and strategies is exchanged in a variety of ways in planned and unplanned meetings. 
Second, the agents in a cluster share similar technological traditions and views which have developed over time. They are based on similar day-to-day routines and problem-solving, and a joint history of regular F2F communication. Through this, new information and technologies are easily understood. When people of a similar technological background and realm of experience in a region converse with one another, they automatically know what others are talking about. Highly-skilled, experienced specialists which have lived in a region for a longer time period know one another and have already become acquainted with several firms and organisations as a result of switching jobs in the area. As positions change hands, knowledge that would be difficult to acquire by other means is transferred between firms (Malmberg and Power 2005).

Third, through a shared history of relationships, firms learn how to interpret local buzz and make good use of it. As a result, communities of practice become more rooted over time (Wenger 1998). This helps to transfer information and knowledge in a precise manner, interpret new information in the context of a cluster's technological competence and extract those knowledge parts which might be valuable in future applications. All of this is possible because co-presence and ongoing F2F encounters in a cluster enhance the likelihood that people will develop compatible technological outlooks and interpretative schemes. It provides a setting conducive to the development of joint institutions (Amin and Thrift 1995).

Interaction occurs through ongoing transaction relations between regional firms, even if their extent is limited, but also through cross-corporate involvement in community activities, industry associations, clubs, and the like. The advantages of permanent co-presence and frequent F2F interaction are further supported by the fact that the firms draw from a joint regional labour market characterised by job mobility and overlapping competencies (Malmberg and Maskell 1997; Malmberg and Power 2005). Through these processes, local buzz is circulated and reinforced. Permanent co-location offers the potential for integrational and informational 
advantages of $\mathrm{F} 2 \mathrm{~F}$ interaction to become part of the institutional structures available to local agents. In many ways, this serves to establish and deepen relational proximity and trust (Amin and Cohendet 2004; Bathelt 2006). It helps establish reliable conditions for economic interaction and configure durable inter-firm relationships.

We have to be careful though in over-generalising these findings (Bathelt, Malmberg and Maskell 2004). In one way or another, they might be observable in many different cluster configurations but the exact mechanisms on which different community types are based can be quite heterogeneous (Amin and Roberts 2008). Consequently, the role of local buzz in different sectors may be rather different, as some industries (e.g. fashion products) might, for instance, require more buzz than others (e.g. steel production). Especially in industries that are formed around epistemic communities (such as nanotechnology and biotechnology), local buzz may play a limited role or be replaced through relational ties that span across distance (e.g. Moodysson 2008) - although Gertler and Levitte (2005) found evidence of buzz linkages. Similar tendencies might prevail in knowledge-intensive and professional services (Faulconbridge 2006). Furthermore, industry or service agglomerations such as software, in which firms are linked to different value chains, likely experience little local buzz due to their heterogeneous orientation (Trippl, Tödtling and Lengauer 2009), supporting the findings of Amin and Roberts (2008).

From research on path-dependent developments we also know that problems can develop if local communication patterns become too rigid and inward-looking, preventing trans-local knowledge flows and necessary adaptations to market and technology changes. Negative technological lock-in, or institutional hysteresis, can occur, particularly related to rigid institutional conditions and/or externalities (Arthur 1988; Setterfield 1993). From a spatial perspective, negative lock-in can result in a situation where localised industrial systems collectively run into problems due to rigid technological and organisational structures (Hassink 
2005; Martin and Sunley 2006; Asheim, Cooke and Martin 2006). Examples include the structural crises of the coal-steel complex in the German Ruhr area (Grabher 1993) or the watch industry in the Swiss-French Jura Arc (Maillat, Léchot, Lecoq and Pfister 1997). Too much local interaction may lead agents to rely too heavily on existing technologies and well-established problem solutions (Granovetter 1973). Through this, they can lose their openness to new solutions; clusters might, in turn, become insular systems vulnerable to external shifts.

This scenario indicates that, although local F2F interaction patterns can provide important advantages to innovative firms, within permanent cluster settings their benefits are sometimes subject to limitations. In other words, the focus on local F2F encounters does not necessarily provide a sufficient basis for ongoing innovation and competitive success. As will be argued below, important inputs can be acquired through systematic interaction and knowledge acquisition outside the cluster setting.

\section{Organisational co-presence in global networks}

In a cluster, spatial proximity and shared institutional, social, and cultural characteristics create conditions for firms to engage in economic transactions and develop long-term produceruser relations, especially if they share a common knowledge basis and similar goals within a particular value chain (Ford 1980; Rallet and Torre 1999). As argued above, it is necessary to move beyond internal cluster interaction to generate long-term growth and competitiveness. Trying to establish and maintain interregional and international linkages is, however, not a routine process with guaranteed success, especially if firms are inexperienced in this respect and if substantial uncertainties arise regarding the coordination of production and knowledge acquisition. This applies in similar ways to most economic contexts, even in low-technology industries (Gereffi, Humphrey and Sturgeon 2005) and in professional services such as consulting 
and law firms (Glückler 2006; Jones 2007). One way to overcome this uncertainty is to establish "organisational proximity" by merging with or acquiring complementary firms in other parts of the world to create reliable conditions for future economic interaction and wider market access (Torre and Rallet 2005; Boschma 2005; Rallet and Torre 2009). International mergers and acquisitions require a certain degree of cognitive proximity between the firms involved to enable the respective agents to communicate more easily and integrate their different cultures into a new overarching structure (Nooteboom 2000). This is especially important in complex technologies with a risk of unintended technological spillovers. At the same time, the firms' capabilities must be sufficiently different from one another to allow them to benefit from interactive learning processes. While international mergers and acquisitions can be viewed as processes bridging multiple distances and establishing a framework for closer inter-firm linkages at an international scale, the same processes can involve substitution and create stress on existing network relations at the regional level.

However, this argument of different types of proximities which can be substituted for one another may detract from the limitations to interaction that firms face due to their particular spatial settings. In the context of global production chains or peripheral locations, for instance, firms do not easily find adequate partners for near-by transactions. They have no choice but to establish linkages over space providing access to distant products, markets, and technologies developed elsewhere. F2F interaction in local context is often not an option for these firms. Especially in global production contexts, interaction is not based on permanent F2F contact (Dicken, Kelly, Olds and Yeung 2001; Henderson, Dicken, Hess, Coe and Yeung 2002; Humphrey and Schmitz 2002). It often relies on a mixture of different types of more or less hierarchical network relations which are derived from existing ties, organisational bonds, or even repeated visits to international trade fairs. Although this applies to a wide range of sectors ranging 
from clothing to toy and cell phone production, the specific governance forms that develop are quite different depending on the degree of product complexity, the degree of codification, and the capability of the supplier base (Gereffi, Humphrey and Sturgeon 2005).

A single specific distance to be minimised in order to establish regular F2F interaction usually does not exist in complex spatial production arrangements, in which firms serve global markets and cooperate with partners located in different parts of the world. From the perspective of market access in the automobile supplier sector, it may be imperative for firms to be close to their major markets in order to learn from interaction with customers and customise products (Depner 2006). Similar processes might lead to so-called "piggy-backing” (Glückler 2006). From the view of research and development, it might be more important to have engineering facilities close to production to benefit from constant feedback, failure, and learning-by-doing (Dicken, Kelly, Olds and Yeung 2001). Depending on which aspect dominates, the locational and organisational structure of firms can be quite different. No matter how and where marketing, production, or research and development are established, any setting is likely associated with proximities on one end and distances on the other. A single plant within a cluster that integrates all corporate functions could, under these circumstances, cause problems because of large distances to major international markets. Geographical proximity and "being there" are important issues of corporate organisation (Gertler $1995 ; 2004$ ) but we have to specify exactly which proximities are key, and in which combination: i.e. proximity to markets, production, and/or knowledge pools.

To sum up, spatial proximity and permanent F2F interaction might be possible with some relevant agents in the value chain but not with all. This is clearly not an exception but the rule. Many firms have learned how to organise economic interaction and knowledge creation without permanent co-presence and have developed spatial configurations which work well without 
requiring co-location and F2F interaction on a daily basis. These settings rely on "organised proximity" (Rallet and Torre 2009) between the respective economic agents and have become expressions of new geographies of circulation through which knowledge can be created and exchanged at a distance (Thrift 2000; Amin and Cohendet 2004). An example for such temporary interaction in organised F2F encounters encompasses multinational firms within which managers go back and forth between different sites in different countries (Wickham and Vecchi 2008). Through this, they generate a context similar to co-presence between distant places. Another example is given by temporary learning processes and knowledge exchange during international trade fairs (Borghini, Golfetto and Rinallo 2006; Maskell, Bathelt and Malmberg 2006).

In attempting to better understand organisational processes developed by firms that are successfully collaborating and innovating in the absence of permanent co-location, it is important to take a closer look at the effect computer-mediated technologies have on communication. This will be done in the following sections.

\section{Computer-mediated communication (CMC) and social psychology theorising}

While the preceding section suggests that permanent or regular F2F contacts are of central importance to processes of economic interaction and knowledge creation in many industries, such encounters are limited in global production contexts. Instead, firms are increasingly relying on virtual communication through new information and communication technologies to organise production, research, and market interaction. As has been demonstrated in experimental observations in social psychology research, F2F interaction can, in part, be supplemented by other forms of computer-mediated interaction. Social presence theorists have, however, long 
stressed the structural differences that exist between $\mathrm{CMC}$ and F2F interaction; especially those related to the absence of non-verbal, vocal, and physical cues (Walther, Loh and Granka 2005). ${ }^{3}$ Five fundamental differences between these two modes of communication are discussed below. Understanding these differences is critical to assessing where and how CMC can support, or even replace, F2F interaction based on permanent co-presence.

The first difference concerns media richness. Scholars in the field have noted that the richness of a communication medium determines its ability to reduce uncertainty and resolve ambiguities or equivocality (Song, Berends, van der Bij and Weggeman 2007). Based on the availability of feedback and multiple cues, as well as language variety and personal focus, communication media can be ordered along a spectrum from rich (e.g. F2F) to lean (e.g. a written document). $\mathrm{CMC}$ technologies are generally regarded as less rich, implying that their capacity to support information exchange under ambiguity is weak (Sproull and Kiesler 1991). Wainfan and Davis (2004) summarize findings from hundreds of studies on virtual collaboration involving groups of agents interacting in both social and workplace settings. While the authors have argued that video-conferencing is reasonably similar to F2F communication in terms of media richness, they have also noted that resolution limitations often challenge their participants' interpretation of body language and gestures, especially as groups get larger. Other studies highlighted by Wainfan and Davis (2004) have noted that participants in video-conferences may find it difficult to identify a remote speaker and attain mutual gaze (Olson and Olson 2003).

${ }^{3}$ Social presence theorists have studied the precise mechanisms of inter-personal communication and interaction in situations characterised by co-presence and F2F contact between individuals, and how different cues affect the outcomes of this process compared to situations with less "social presence", such as text-based CMC. 
Second, the richness of a communication medium influences an interactant's capacity to build relationships resulting from less sociable, relational, understandable, and effective communication. In terms of social presence, the fewer the channels or cues available within a medium, the less attention an individual pays to the presence of other social participants, and the less likely the establishment of networks through this form of communication. This has been demonstrated in studies based on controlled experiments where participants were asked to communicate using synchronous computer chat dyads (Walther, Loh and Granka 2005). Most $\mathrm{CMC}$ is low in social presence compared to F2F interaction, which has implications for trust building.

The third difference between F2F interaction and CMC with respect to knowledge dissemination concerns the ability to transfer tacit knowledge. Tacit knowledge - which is implicit and personal to an agent and is context-specific - is not easily transferable to other agents (Malmberg and Maskell 1997). The dissemination of tacit and situated knowledge is enabled by intensive interaction, and the joint observation and operation of material artefacts. Thus, in addition to supporting an array of verbal and non-verbal cues, co-location allows partners to have access to the same observational cues and to engage in the same practices, thereby enhancing the dissemination of tacit knowledge. Song, Berends, van der Bij and Weggeman (2007) demonstrate this using empirical data collected from 277 high-technology firms in the U.S. and 125 hightechnology firms in the Netherlands. While video-conferencing can assist in the verbal transfer of tacit knowledge as practiced in processes of global strategy adjustments in multinational corporate networks, the learning-by-doing component of tacit knowledge dissemination limits its applicability in the context of economic production and innovation.

Fourth, the value of co-location is significantly augmented by the fact that it requires little effort in initiating communication. Co-location increases the amount of communication that 
occurs between agents as it reduces the effort required to make intentional visits and increases chances for unexpected and spontaneous encounters, although possibilities for this might also arise in virtual communities (von Hippel 2001; Moriset and Malecki 2009).

Fifth, some CMC technologies, however, have the ability to overcome spatial and social limits of interaction. For example, asynchronous communication can cross time zones, and mass e-mails offer employees the opportunity to communicate with a larger number of staff than would be possible through F2F interaction alone. These are generic findings important for any economic activity that requires repeated interaction and direct contact. A further advantage of CMC is its memory function, which makes possible both the retention and retrieval of knowledge after the fact, enabling, for instance, a timely scheduling of production runs and just-in-time deliveries.

In contrast to the previous points which have largely emphasized the disadvantages of CMC, such technologies offer alternate opportunities not readily available in F2F encounters. In reversing the findings of social presence theorists, we might find that $\mathrm{CMC}$ is well suited for the transfer of explicit and unambiguous knowledge. However, competing theories suggest there may be even more informational advantages to be accrued from CMC; especially with regard to the formation of social relations. In particular, a substantial body of research has contested the presumed differentiation of verbal and non-verbal cue functionalities, at least with respect to their outcome (Garton and Wellman 1993). Two conceptions have particularly challenged conventional beliefs:

(i) Social information processing theory. This view contends that individuals deploy whatever communication cues they have at their disposal when motivated to form impressions and develop relationships. When non-verbal cues are unavailable, as is the case with text-based CMC, users adapt their language, style, and other cues to such purposes. Furthermore, this position rejects the notion that $\mathrm{CMC}$ is inherently impersonal and that relational information is 
inaccessible to $\mathrm{CMC}$ users. Rather, this perspective suggests that users employ the verbal features of $\mathrm{CMC}$ to convey relational information that would normally be expressed through non-verbal cues in F2F settings (Walther, Loh and Granka 2005). Hancock and Dunham (2001) conclude from a social-networking study comparing first impressions formed in person and online, that these impressions are relatively incomplete and weak in the case of CMC. However, the authors find that impressions formed in CMC become more comprehensive and developed over time, as participants seek out relevant information about each other. When individuals disclose information about themselves and interrogate one another online, they reduce uncertainty, are better able to form impressions of each other, and compensate for the social cues lost to the medium. Thus, CMC collaborators may also be able to engage in trust-building activities by disclosing contextual and personal information not necessarily discussed in F2F settings where such information is physically apparent.

(ii) Equilibrium theory. ${ }^{4}$ This view posits that communicators dynamically adapt levels of gaze, proximity, and other behaviours indicative of intimacy to normative levels based on culture and need for affiliation. In dyadic interaction, agents who seek "equilibrium comfort levels" will adjust their behaviours accordingly. Where one agent is lacking communicative cues, the other will compensate in order for the two parties to successfully communicate. Over time, this might

${ }^{4}$ Here, we have to keep in mind that the term "equilibrium" is used differently in social psychology, as compared to economics or economic geography, although some similarities exist. It is not related to aspects of optimal economic exchange. Instead, an equilibrium refers to a situation in which two individuals each receive just enough information and knowledge about the other person's intentions and context so that they are able to adequately communicate at an "equilibrium comfort level", willing to develop trust and engage in transactional type behaviour. The term "equilibrium level of intimacy" is similar to the preceding definition, and encompasses the basic requisite level of physical closeness for communication to occur, trust to develop, and transactions to arise between individuals. 
stimulate reciprocal behaviour through additional cue switches. Extending this conception to $\mathrm{CMC}$, individuals will overcompensate with their verbal behaviour by, for example, asking more questions and disclosing more information, so that an "equilibrium level of intimacy" can be reached. Olson and Olson (2003) have examined group interaction in various remote and colocated settings, involving controlled laboratory experiments, as well as in the context of international project collaboration between scientists and researchers. They suggest that, especially in the initial stage of collaboration when benefits from working with remote colleagues may be particularly significant, collaborating agents show a willingness to endure the costs of frustration and imperfect connections afforded by electronic communication strategies. When incentives are strong enough, new practices will emerge, associated with new local and non-local forms of organising production and innovation.

As many of these findings have been made outside direct economic context, such as social-networking, their results are often generic and relate to the communication of specific messages and knowledge, coordination of tasks between spatially separated individuals, and establishing and maintaining social relations over space. However, this research is of importance to a broad range of economic activities in day-to-day contexts of negotiations, continuous production adjustments, problem-solving and search processes, strategy discussions, and the like - albeit that this takes place in varied forms for different industries and corporate functions.

Furthermore, these views clearly raise questions regarding the implicit superiority of local F2F-based encounters over $\mathrm{CMC}$ in distant interaction. Although there are limitations to economic interaction, the systematic use of CMC enables complex interaction, and can stimulate network formation even without frequent F2F contact. If we include opportunities of utilising video-based $\mathrm{CMC}$ formats and the combination of these virtual encounters with occasional planned F2F meetings, the range of possibly efficient spatial configurations involving local and 
non-local F2F and computer-mediated exchanges drastically widens. It becomes feasible to develop different spatial configurations and strategies, depending on existing business opportunities within a particular value chain. As a consequence, there might not be specific spatial-organisational best-practices per se. Local industry clusters are certainly an organisational option, but it is questionable whether they should be viewed as the most efficient one in processes of learning and innovation, compared to other trans-local organisational forms.

The next section will substantiate this in specific economic settings by presenting empirical findings in the context of corporate innovation projects and group collaboration.

\section{Virtual vs. F2F collaboration in groups and corporations: findings from social psychology research}

Traditionally, a primary strategy for ensuring a high level of knowledge dissemination in multinational firms has been the co-localisation of R\&D staff as in the case of Philips Electronics (Song, Berends, van der Bij and Weggeman 2007). Innovative activities in the modern knowledge economy, however, involve an increasing social division of labour in many industries that has become much more dispersed (Lundvall and Johnson 1994), and now also includes professional service industries (Faulconbridge 2006). The impetus behind this trend might be to bring R\&D closer to foreign markets, to tap into new knowledge pools, or to reduce labour costs. In addition to co-location and F2F interaction, firms increasingly use virtual forms of collaboration in their innovation processes, such as e-mail, Skype, and video-conferencing. This has been shown by Hossain and Wigand (2004) in their broad summary of other empirical research of mostly controlled laboratory experiments. Investigations of team-based collaboration show that, depending on the task at hand and the contextual setting, innovation over distance can 
be quite successful. Of course, such collaboration can also fail if organised in an unfavourable context or with unaligned expectations.

Contextual differences between F2F interaction and CMC have been shown to affect both the process and outcome of communication. For example, Wainfan and Davis (2004) suggest that the group structure in $\mathrm{CMC}$ is often broader and more agile than in F2F teams. Accordingly, there is greater breadth in collaboration themes due to a wider involvement of experts. From their controlled experiments involving group problem solving, Slevin, Boone, Russo and Allen (1998) have shown that agility, resulting from quicker response times and the ability to access additional information, is often easier and faster when participants operate close to their work locations. If production sites are spatially distributed, a dispersed project setting might thus work better than a F2F setting where participants have to leave their workplaces for segments of the project - a result that might be transferable to a situation in which new machinery has to be adjusted to different local plant settings in a trans-national context, or in which new software is developed out of several decentralised engineering service firms in different countries.

Although it might be harder to form social networks in CMC compared to F2F contexts, it is also more difficult to distract or deflect the participants' attention by involving them in side conversations. In reducing non-verbal cues, other factors such as power, status, and common ground - based, for instance, on personal appearance or appeal - become less important in corporate decision-making through $\mathrm{CMC}$. In the localised context of a firm, contextual cues such as seating position, office location, and even clothing have been found to influence communication patterns during employee meetings, as demonstrated in early laboratory experiments conducted by Dubrovsky, Kiesler and Sethman (1991). Sproull and Kiesler (1992) have examined electronic mail correspondence in small and medium-sized firms from various industries finding that individuals using $\mathrm{CMC}$ feel less constrained by conventional norms and 
rules of behaviour. The lack of "social baggage" attached to electronic messaging, for instance, may help overcome some detrimental hierarchical and social structures impeding decision making within a group setting. Power and status are harder to detect and, therefore, play a less prominent role in interaction. As it may not be possible to adequately share visual aids, of course, this may complicate the innovation process. At the same time, it also opens opportunities for variation and deviation from existing innovation trajectories because communication patterns and decision-making may be less subject to power asymmetries. Of course, there is also a danger that new social baggage is reintroduced with the implementation of sophisticated video-conferencing technologies which try to reproduce F2F settings.

While analyses examining the nature of group processes mediated through $\mathrm{F} 2 \mathrm{~F}$ interaction and $\mathrm{CMC}$ differ with respect to the exact mode of communication, task type, and individual and group characteristics, researchers have found consistent results in laboratory-based settings and non-laboratory, real-world observations (Wainfan and Davis 2004). It is consistently reported in the literature that synchronous, text-based conferencing groups take longer to complete assigned tasks than F2F groups (McGuire, Kiesler and Siegel 1987; Weisband 1992; Reid, Ball, Morley and Evans 1997). Consensus frequently follows a leader's push for his or her preferred solution while interaction patterns in CMC settings show more evenly distributed participation. This effect also emerges during video-conference collaboration despite its closeness to F2F interaction, as shown, for instance, in a controlled experiment of group decision-making (Wainfan and Davis 2004). Depending on the context, this can be an advantage in the beginning of a decision-making process or a disadvantage in finalising a project under time constraints. Furthermore, experimental studies have shown that groups using CMC tend to make riskier or more extreme decisions than in F2F settings (Kiesler and Sproull 1992). 
With less overall participation and more difficulty reaching consensus, studies documented by Wainfan and Davis (2004) have shown that CMC participants make more explicit proposals, defer less to high-status members, and are less inhibited than F2F collaborators. Rice's (1984) experimentation with small work groups in competition settings showed already in the 1980s that when faced with a dilemma, F2F groups would begin by analysing the problem, whereas CMC collaborators start discussion by proposing a solution. In some cases, group members in CMC suggest solutions before even listening to the thoughts of other participants. This again points to the potential of CMC settings to break with existing problem solutions and generate opportunities for radical innovations, similar to the argument developed by Granovetter (1973). Again, although many laboratory experiments, on which these findings are based, are not conducted in an explicit economic context, they apply to a broad range of generic activities that can be found in many different industry settings within and between firms, in local and translocal communication, and in routine and non-routine economic interaction.

In the context of innovation projects in multinational firms, Song, Berends, van der Bij and Weggeman (2007) have documented interesting findings regarding the nature of collaboration and its outcomes. In their field research on U.S. and Dutch high-technology firms, Song, Berends, van der Bij and Weggeman (2007) find that knowledge dissemination between agents is greatest when both settings are combined. There appear to be parts of innovation processes where F2F meetings are key to the development of new ideas and concepts, while other parts benefit from work at dispersed workplaces with regular CMC adjustments. Permanent co-location may foster knowledge dissemination within $\mathrm{R} \& \mathrm{D}$ but impede knowledge exchange between $\mathrm{R} \& \mathrm{D}$ and production. At the corporate level, knowledge exchange in strategic business areas also requires that uncertainties and ambiguities are reduced, and that both explicit and tacit knowledge in both weak and strong relationships, planned and unplanned meetings, and both nearby and far away 
are transferred. Although the exact spatial form and governance mechanisms may differ widely according to economic context, this suggests that optimal innovation conditions require that colocation is complemented by CMC technologies and alternative organisational configurations. There is a growing literature which emphasises the economic significance of such virtual usercommunities (e.g. von Hippel 2001; Jeppesen and Molin 2003; Grabher, Ibert and Flohr 2008). The findings presented resonate well with the SECI model by Nonaka and Takeuchi (1995) in which the process of knowledge generation in large corporations is described as one of transforming and recombining existing knowledge bases in a series of successive stages. In different stages of this transformation and with different tasks, the context for interaction, or "ba", 5 chosen to support innovation switches back and forth from co-located to dispersed settings for knowledge transfers and learning. The project ecologies in the advertising industry are a good example that shows how project collaboration can shift back and forth from co-located to dispersed and virtual work settings without a pre-determined best-practice configuration (Grabher 2001).

Olson and Olson (2003) have similarly examined virtual collaborative practices carried out in the context of multi-year international project collaboration between graduate researchers and scientists. With respect to cases of failed remote collaborations, a number of valuable observations have been made. In situations where collaborative work relies on video and online conferencing to substitute for F2F communication, agents spend nearly more time managing

${ }^{5}$ The Japanese concept of "ba" refers to the organisational contexts in which individuals interact at a specific time and place. These contexts are fluid and, due to reflexive social practices, constantly changing. The existence of "ba" allows information to be interpreted in a meaningful way and eventually results in new knowledge. Although "ba" is a social concept, its empirical manifestations are associated with distinct spatialities. 
themselves and their work through information and communication technologies than actually doing work. In projects in which the stress of using CMC over time increases, interaction frequency seems to fall, and the likelihood of communication breakdown, and even project failure, increases. In response to such conditions, firms reorganise operations so that stressful, highly interactive work can be done in one location. Other dilemmas with communication technologies are associated with technical deficiencies. Olson and Olson (2003) note that in many cases, technical difficulties, including the quality of visual display or audio, affect interactivity negatively. In video interaction, for instance, participants have difficulties identifying which remote partner speaks and do not respond without being explicitly addressed by name. Over time however, participants tend to adapt to this situation by identifying themselves before speaking, and using more formal protocols for turn-taking. Generally, we can expect that such difficulties disappear over time with the development of new video technologies.

\section{Conclusion}

As demonstrated above, advancements in information and communication technologies have substantially changed the means through which firms conduct business. Studies in social psychology have shown that $\mathrm{CMC}$ and F2F interaction remain highly contingent upon the task being carried out. As technology develops, we expect such contingencies to diminish, but not at the rate once expected (Leamer and Storper 2001). Relevant studies examining F2F interaction and $\mathrm{CMC}$ demonstrate that the two mediums possess unique properties. Each medium has its relative strengths and weaknesses which play themselves out differently during different tasks. In this paper, we have combined findings from economic geography and social psychology to provide a deeper, more differentiated understanding of these processes. We view this analogous to Thrift (2004) as an opportunity to extend "conventional geographical imagination" by going 
beyond the narrow boundaries of the discipline. Although findings in social psychology often result from laboratory experiments and social-networking studies without direct economic context, their results relate to generic configurations of communication and interaction that apply to a broad range of economic activities - albeit that the precise mechanisms, of course, depend on the specific context.

In particular, there are at least three ways in which findings from social psychology can enrich the work of economic geographers: First, the research conducted in social psychology has over a long time presented evidence that - and explanations why - economic processes do not necessarily have to be based on or be organised in spatial proximity. Following Oinas (1999), economic geographers have sometimes assumed or hoped - rather than actually demonstrated that the local is the decisive spatial scale for economic interaction and knowledge generation; and they have paid relatively little attention to explaining why this might or might not be case. In much of this literature, there appears to be insufficient understanding of the exact mechanisms and processes which make F2F interaction particularly valuable. Second, the arguments presented in this paper suggest that it might not be that useful after all to think in terms of a hierarchy of discrete spatial scales with pre-defined sets of advantages that determine optimal spatial configurations for economic interaction and knowledge creation. Findings in social psychology, instead, suggest that configurations of production and research are contingent upon socioinstitutional, political, and cultural contexts and experiences. This should, in our interpretation, be seen as an opportunity to avoid regional economic lock-in, rather than as a threat to localised economic structures per se. Third, these results indicate that a potential reinvigoration of regional/national production configurations in the future, associated with the necessities of global climate change and the effects of higher fuel and related transportation costs, may go hand in hand with processes of trans-local knowledge generation and learning. 
In response to the inefficiencies of $\mathrm{CMC}$ and the importance of geographic proximity, corporate actors explore organisational structures combining both $\mathrm{CMC}$ with $\mathrm{F} 2 \mathrm{~F}$, thus enabling knowledge generation even over great distances. For Torre and Rallet (2005), a solution lies in the temporary mobility of individuals. The need for F2F interaction in terms of knowledge exchange does not necessitate that individuals permanently co-locate. What it requires is that individuals meet regularly in certain time intervals. In some circumstances, problems can be solved through the mobility of individuals, as in the case of business travelling (Wickham and Vecchi 2008). In other cases, individuals collaborating in projects typically only need to meet in person during particular phases in the innovation process, especially during times of high complexity and uncertainty. Through regular attendance at international trade fairs, for instance, firms are able to find suitable partners to complement their needs, establish trust with distant partners, and undertake the first steps toward the development of durable inter-firm networks in research, production, and/or marketing (Maskell, Bathelt and Malmberg 2006). Temporary F2F contact during these events opens up possibilities for knowledge creation, search for solutions and technologies, networking, and market development - at a global basis in virtually all industries (Rinallo and Golfetto 2006). Agents benefit from integrational and informational cues transported through repeated, intensive, often short F2F encounters which lead to a rich communication and information ecology referred to as "global buzz" (Schuldt and Bathelt 2011).

Such organised proximity, of course, is not a purely geographical concept: it is relational in character and urges greater interaction among the members of a project, organisation, or value chain (Bathelt 2006; Faulconbridge 2007; Amin and Roberts 2008; Rallet and Torre 2009). It involves the establishment of a collective culture that generates shared interpretations of new information even if the agents are located in different places. Such commonality in thinking and problem-solving is critical to knowledge generation and innovation. 
Our findings of the roles of F2F interaction and CMC support Leamer and Storper (2001: 658) who suggest that "[t]he Internet will probably reinforce the roundaboutness of production and hence of the importance of face-to-face contact, though it will also probably make possible greater linkages between different localised clusters at very long distances." In scenarios where proximity is simply untenable, the value of virtual interaction using modern information and communication technologies dramatically increases. In these cases, actors are quite willing to put up with and overcome the deficiencies of virtual interaction. Different best-practices emerge as individuals cope with the latest technologies.

Trade-offs are inevitable and staying competitive requires pinpointing a firm's own mixture of settings for interacting in production, distribution, and innovation. Understanding what tasks are most sensitive to the communication medium and utilising those better suited is crucial to mapping out this mixture. Under all circumstances, we have to keep in mind that one decisive disadvantage of $\mathrm{CMC}$ compared to $\mathrm{F} 2 \mathrm{~F}$ communication is related to difficulties in establishing initial trust. While this may require that complex innovation projects over distance have to involve agents already sharing trust from former cooperation in a co-localised setting, it does not rule out many other projects based on CMC even in complex contexts.

Just as sound innovation strategies incorporate advantages of both local and trans-local, or even global, integration, so too do firms increasingly rely on CMC and F2F interaction in combination with each other. To argue that virtual interaction will eventually eliminate the benefits accrued from geographic proximity makes little sense when evaluating complex economic realities. It also appears misleading to assume a superiority of local over non-local economic networks. Instead, we recognise that modern information and communication technologies have allowed distant and close-by collaboration to occur simultaneously. Both phenomena incur different costs, and generate different benefits. The firms and networks best 
able to make use of both options will likely develop a high degree of flexibility and an "integrative" competitive advantage in the globalising knowledge economy of the future.

\section{Acknowledgements}

Different parts of this paper were presented at various conferences between 2008 and 2010: the Annual Meeting of the Association of American Geographers in Boston, the Conference on Industrial Cluster and Regional Development in Kaifeng (China), the Symposium "Knowledge and Economy" in Heidelberg, the Summer Institute in Economic Geography in Manchester, the Panel on Technology Clusters in Charlottetown (organised by the Network on North American Studies in Canada), and the Summer School on the "Management of Creativity in an Innovation Society" at HEC Montréal. We would like to thank the participants of these meetings, especially Filippo Celata, Neil Coe, Patrick Cohendet, Roberta Comunian, Tim Elrik, Rikard Eriksson, Jan Fagerberg, John Harrison, Franz Huber, Christian Ketels, Ed Malecki, Ulf Matthiessen, Peter Meusburger, Grzegorz Micek, Bronwyn Parry, Eric Sheppard, Laurent Simon, Kevin Ward, Henry Yeung, and Gang Zeng, for stimulating comments and suggestions. Further, we would like to thank the anonymous reviewers and, especially, Michael Samers for thoughtful remarks which greatly helped in sharpening our arguments.

\section{References}

Allen, J. (1997): Economies of power and space. In: Lee, R. and Wills, J. (Eds.): Geographies of Economies. London: Arnold, pp. 59-70.

Amin, A. (2004): Regions unbound: towards a new politics of place. Geografiska Annaler $\mathbf{8 6}$ B: $33-44$. 
Amin, A. and Cohendet, P. (2004): Architectures of Knowledge: Firms, Capabilities, and Communities. Oxford, New York: Oxford University Press.

Amin, A. and Roberts, J. (2008): Knowing in action: beyond communities of practice. Research Policy 37: 353-369.

Amin, A. and Thrift, N. (1995): Living in the global. In: Amin, A. and Thrift, N. (Eds.): Globalization, Institutions, and Regional Development in Europe. Oxford, New York: Oxford University Press, pp. 1-22.

Arthur, W. B. (1988): Competing technologies: an overview. In: Dosi, G., Freeman, C., Nelson, R. R., Silverberg, G. and Soete, L. L. G. (Eds.): Technical Change and Economic Theory. London, New York: Pinter, pp. 590-607.

Asheim, B. T. (2000): Industrial districts. In: Clark, G. L., Feldman, M. P., and Gertler, M. S. (Eds.): The Oxford Handbook of Economic Geography. Oxford: Oxford University Press, pp. 413-431.

Asheim, B., Coenen, L. and Vang, J. (2006): Face-to-face, buzz and knowledge bases: sociospatial implications for learning, innovation and innovation policy. In: Coenen, L. (Ed.): Faraway so Close: The Changing Geographies of Regional Innovation. Lund: Department for Social and Economic Geography, Lund University, pp. 207-234.

Asheim, B., Cooke, P. and Martin, R. (2006): The rise of the cluster concept in regional analysis and policy: a critical assessment. In: Asheim, B., Cooke, P. and Martin, R. (Eds.): Clusters and Regional Development: Critical Reflections and Explorations. London and New York: Routledge, pp. 1-29.

Bathelt, H. (2006): Geographies of production: growth regimes in spatial perspective 3 - toward a relational view of economic action and policy. Progress in Human Geography 30: 223236. 
Bathelt, H. (2007): Buzz-and-pipeline dynamics: toward a knowledge-based multiplier model of clusters. Geography Compass 1 (6): 1282-1298.

Bathelt, H., Malmberg, A. and Maskell, P. (2004): Clusters and knowledge: local buzz, global pipelines and the process of knowledge creation. Progress in Human Geography 28: 31 56.

Bathelt, H. and Schuldt, N. (2008): Between luminaires and meat grinders: international trade fairs as temporary clusters. Regional Studies 42: 853-868.

Birdwhistell, R. L. (1970): Kinetics and Context. Philadelphia: University of Philadelphia.

Borghini, S., Golfetto, F. and Rinallo, D. (2006): Ongoing search among industrial buyers. Journal of Business Research 59: 1151-1159.

Boschma, R. A. (2005): Proximity and innovation: a critical assessment. Regional Studies 39: 6174.

Carrasco, J.-A., Wellman, B. and Miller, E. (2008): How far - and with whom - do people socialize? Empirical evidence about distance between social network members. Transportation Research Record 2076 (2008): 114-122.

Crang, P. (1997): Cultural turns and the (re)constitution of economic geography. In: Lee, R. and Wills, J. (Eds.): Geographies of Economies. London, New York: Arnold, pp. 3-15.

Depner, H. (2006): Transnationale Direktinvestitionen und kulturelle Unterschiede: Lieferanten und Joint Ventures deutscher Automobilzulieferer in China (Transnational Direct Investments and Joint Ventures of German Automobile Suppliers in China). Bielefeld: Transcript.

Dicken, P., Kelly, P. F., Olds, K. and Yeung, H. W.-c. (2001): Chains and networks, territories and scales: towards a relational framework for analysing the global economy. Global Networks 1: 89-112. 
Dubrovsky, V. J., Kiesler, S. and Sethna, B. N. (1991): The equalization phenomenon: status effects in computer-mediated and face-to-face decision making groups. Human-Computer Interaction 6: 119-146.

Enright, M. J. (2003): Regional clusters: what we know and what we should know. In: Bröcker, J., Dohse, D. and Soltwedel, R. (Eds.): Innovation Clusters and Interregional Competition. Berlin, Heidelberg: Springer, pp. 99-129.

Faulconbridge, J. R. (2006): Stretching tacit knowledge beyond a local fix? Global spaces of learning in advertising professional service firms. Journal of Economic Geography 6: 517-540.

Ford, D. (1980): The development of buyer-seller relationships in industrial markets. European Journal of Marketing 14 (5/6): 339-353.

Fukuyama, F. (1995): Trust: The Social Virtues and the Creation of Prosperity. New York: Free Press.

Garton, L. E. and Wellman, B. (1993): Social Impacts of Electronic Mail in Organizations: A Review of the Research Literature. Ontario Telepresence Project, Toronto (URL: http://hdl.handle.net/1807/368, date accessed December 27, 2008).

Gereffi, G., Humphrey, J. and Sturgeon, T. (2005): The governance of global value chains. Review of International Political Economy 12 (1): 78-104.

Gertler, M. S. (1995): "Being there": proximity, organization, and culture in the development and adoption of advanced manufacturing technologies. Economic Geography 71: 1-26.

Gertler, M. S. (2004): Manufacturing Culture: The Institutional Geography of Industrial Practice. Oxford, New York: Oxford University Press.

Gertler, M. S. and Levitte, Y. M. (2005): Local needs in global networks: the geography of knowledge flows in biotechnology innovation. Industry and Innovation 12: 487-507. 
Gibson, C. B. and Cohen, S. G. (Eds.) (2003): Virtual Teams that Work: Creating Conditions for Effective Virtual Teams. San Francisco: Jossey-Bass.

Glückler, J. (2006): A relational assessment of international market entry in management consulting. Journal of Economic Geography 6: 369-393.

Goffman, E. (1969): Behavior in Public Places. New York: Free Press.

Gordon, I. R. and McCann, P. (2000): Industrial clusters: complexes, agglomeration and/or social networks. Urban Studies 37: 513-532.

Grabher, G. (1993): The weakness of strong ties: the lock-in of regional development in the Ruhr area. In: Grabher, G. (Ed.): The Embedded Firm: On the Socioeconomics of Industrial Networks. London, New York: Routledge, pp. 255-277.

Grabher, G. (2001): Ecologies of creativity: the village, the group, and the heterarchic organisation of the British advertising industry. Environment and Planning A 33: 351-374.

Grabher, G. (2002): Cool projects, boring institutions: temporary collaboration in social context. Regional Studies 36: 205-214.

Grabher, G., Ibert, O. and Flohr, S. (2008): The neglected king: the customer in the new knowledge ecology of innovation. Economic Geography 84: 253-280.

Granovetter, M. (1973): The strength of weak ties. American Journal of Sociology 78: 1360-1380.

Granovetter, M. (1985): Economic action and economic structure: the problem of embeddedness. American Journal of Sociology 91: 481-510.

Hancock, J. and Dunham, P. (2001): Impression formation in computer-mediated communication. Communication Research 28: 325-347.

Hassink, R. (2005): How to unlock regional economies from path dependency? From learning region to learning cluster. European Planning Studies 13: 521-535. 
Henderson, J., Dicken, P., Hess, M., Coe, N. and Yeung, H. W.-c. (2002): Global production networks and the analysis of economic development. Review of International Political Economy 9: 436-464.

Hendry, C., Brown, J. and DeFillippi, R. (2000): Regional clustering of high technology-based firms: opto-electronics in three countries. Regional Studies 34: 129-144.

Hollingshead, A. B. and McGrath, J. E. (1995): Computer-assisted groups: a critical review of the empirical research. In: Guzzo, R. A. and Salas, E. (Eds.): Team Effectiveness and Decision Making in Organizations. San Francisco: Jossey-Bass/Pfeiffer, pp. 46-78.

Hossain, L. and Wigand, R. T. (2004): ICT enabled virtual collaboration through trust. Journal of $\begin{array}{lllll}\text { Computer } & \text { Mediated } & \text { Communication } & \mathbf{1 0} & \text { (1) }\end{array}$ http://jcmc.indiana.edu/vol10/issue1/hossain_wigand.html, accessed February 21, 2008).

Humphrey, J. and Schmitz, H. (2002): How does insertion in global value chains affect upgrading in industrial clusters? Regional Studies 36: 1017-1027.

Jeppesen, L. B. and Molin, J. M. (2003): Consumers as co-developers: learning and innovation outside the firm. Technology Analysis \& Strategic Management 15: 363-383.

Jones, A. M. (2007): More than managing across borders? The complex role of face-to-face interaction in globalizing law firms. Journal of Economic Geography 7: 223-246.

Jøsang, A. (1996): The right type of trust for distributed systems. Proceedings of the 1996 New $\begin{array}{llll}\text { Security } \quad \text { Paradigms } & \text { Workhop, }\end{array}$ (http://sky.fit.qut.edu.au/ josang/papers/Jos1996-NSPW.pdf, accessed February 20, 2008).

Kiesler, S. and Sproull, L. (1992): Group decision making and communication technology. Organizational Behavior and Human Decision Processes 52: 96-123.

Leamer, E. E. and Storper, M. (2001): The economic geography of the Internet age. Journal of International Business Studies 32 (4): 641-665. 
Lundvall, B.-Å. and Johnson, B. (1994): The learning economy. Journal of Industry Studies 1: $23-42$.

Maillat, D., Léchot, G., Lecoq, B. and Pfister, M. (1997): Comparative analysis of the structural development of milieux: the watch industry in the Swiss and French Jura Arc. In: Ratti, R., Bramanti, A. and Gordon, R. (Eds.): The Dynamics of Innovative Regions: The GREMI Approach. Ashgate: Aldershot, Brookfield, pp. 109-137.

Malmberg, A. and Maskell, P. (1997): Towards an explanation of industry agglomeration and regional specialization. European Planning Studies 5: 25-41.

Malmberg, A. and Power, D. (2005): (How) do (firms in) clusters create knowledge? Industry and Innovation 12 (4): 409-431.

Martin, R. and Sunley, P. (2006): Path dependence and regional economic evolution. Journal of Economic Geography 6: 35-437.

Maskell, P., Bathelt, H. and Malmberg, A. (2006): Building global knowledge pipelines: the role of temporary clusters. European Planning Studies 14: 997-1013.

McGuire, T. W., Kiesler, S. and Siegel, J. (1987): Group and computer-mediated discussion. Personality and Social Psychology 52 (5): 917-930.

Mok, D., Wellman, B. and Basu, R (2007): How much did distance matter before the Internet? Social Networks 29 (3): 430-461.

Mok, D., Wellman, B. and Carrasco, J.-A. (2010): Does distance matter in the age of the Internet? Urban Studies 47: 2747-2783.

Moodysson, J. (2008): Principles and practices of knowledge creation: on the organization of "buzz" and "pipelines" in life science communities. Economic Geography 84: 449-469.

Morgan, K. (2004): The exaggerated death of geography: learning, proximity and territorial innovation systems. Journal of Economic Geography 4 (1): 3-21. 
Moriset, B. and Malecki, E. J. (2009): Organization versus space: the paradoxical geographies of the digital economy. Geography Compass 3: 256-274.

Nelson, K. M. and Cooprider, J. G. (1996): The contribution of shared knowledge to IS group performance. MIS Quarterly 20 (4): 409-432.

Nonaka, I. and Takeuchi, H. (1995): The Knowledge-Creating Company. New York: Oxford University Press.

Nooteboom, B. (2000): Learning and Innovation in Organizations and Economies. Oxford: Oxford University Press.

Oinas, P. (1999): Activity-specificity in organizational learning: implications for analysing the role of proximity. GeoJournal 49: 363-372.

Olson, C. and Olson, J. (2003): Mitigating the effects of distance on collaborative intellectual work. Economics of Innovation and New Technology 12 (1): 27-42.

Pinch, S., Henry, N., Jenkins, M. and Tallmann, S. (2003): From 'industrial districts' to 'knowledge clusters': a model of knowledge dissemination and competitive advantage in industrial agglomerations. Journal of Economic Geography 3: 373-388.

Porter, M. E. (1990): The Competitive Advantage of Nations. New York: Free Press.

Porter, M. E. (2003): The economic performance of regions. Regional Studies 37: 549-578.

Preiss1, B. and Solimene, L. (2003): The Dynamics of Clusters and Innovation. Heidelberg, New York: Physica.

Rallet, A. and Torre, A. (1999): Is geographical proximity necessary in the innovation networks in the era of the global economy? GeoJournal 49: 373-380.

Rallet, A. and Torre, A. (2009): Temporary Geographical Proximity for Business and Work Coordination: When, How and Where? SPACES online 2009-02. Toronto, Heidelberg: www.spaces-online.com. 
Reid, F. J. M., Ball, L., Morley, A. and Evans, J. (1997): Styles of group discussion in computermediated decision making. British Journal of Social Psychology 36 (3): 241-262.

Rice, R. E. (1984): Mediated group communication. In: Rice, R. E. and Associates (Eds.): The New Media: Communication, Research and Technology. Beverly Hills: Sage, pp. 129-156.

Rinallo, D. and Golfetto, F. (2006): Representing markets: the shaping of fashion trends by French and Italian fabric companies. Industrial Marketing Management 35: 856-869.

Saxenian, A. L. (1994): Regional Advantage: Culture and Competition in Silicon Valley and Route 128. Cambridge (MA), London: Harvard University Press.

Schuldt, N. and Bathelt, H. (2011): International trade fairs and global buzz, part II: practices of global buzz. European Planning Studies 19: forthcoming.

Scott, A. J. (1988): New Industrial Spaces: Flexible Production Organization and Regional Development in North America and Western Europe. London: Pion.

Setterfield, M. (1993): A model of institutional hysteresis. Journal of Economic Issues 27: 755774.

Short, J., Williams, E. and Christie, B. (1976): The Social Psychology of Telecommunications. New York: Wiley.

Slevin, D. P., Boone, L. W., Russo, E. M. and Allen, R. S. (1998): CONFIDE: a collective decision-making procedure using confidence estimates of individual judgments. Group Decision \& Negotiation 7 (2): 179-194.

Song, M., Berends, H., van der Bij, H. and Weggeman, M. (2007): The effects of IT and colocation on knowledge dissemination. The Journal of Product Innovation Management 24 (1): $52-68$.

Sproull, L. and Kiesler, S. (1992): Connections: New Ways of Working in the Networked Organization. Cambridge, MA: MIT Press. 
Storper, M. (1997): The Regional World: Territorial Development in a Global Economy. New York, London: Guilford.

Storper, M. and Venables, A. J. (2004): Buzz: face-to-face contact and the urban economy. Journal of Economic Geography 4: 351-370.

Storper, M. and Walker, R. (1989): The Capitalist Imperative: Territory, Technology, and Industrial Growth. New York, Oxford: Basil Blackwell.

Swagerman, D. M., Dogger, N. and Maatman, S. (2000): Electronic markets from a semiotic perspective. Electronic Journal of Organizational Virtualness 2 (2): 22-42.

Taylor, M. (2000): Enterprise, power and embeddedness: an empirical exploration. In: Vatne, E. and Taylor, M. (Eds.): The Networked Firm in a Global World: Small Firms in New Environments. Aldershot, Burlington: Ashgate, pp. 199-233.

Thrift, N. (2000): Performing cultures in the new economy. Annals of the Association of American Geographers 90: 674-692.

Thrift, N. (2004): Intensities of feeling: towards a spatial politics of affect. Geografiska Annaler 86 B: $57-75$.

Torre, A. and Rallet, A. (2005): Proximity and localization. Regional Studies 39: 47-59.

Trippl, M., Tödtling, F., and Lengauer, L. (2009): Knowledge sourcing beyond buzz and pipelines: evidence from the Vienna software sector. Economic Geography 85: 443-462.

Uzzi, B. (1997): Social structure and competition in interfirm networks: the paradox of embeddedness. Administrative Science Quarterly 42: 35-67.

von Hippel, E. (2001): Innovation by user communities: learning from open-source software. MIT Sloan Management Review 42 (2): 82-86. 
Wainfan, L. and Davis, P. K. (2004): Challenges in Virtual Collaboration: Videoconferencing, Audioconferencing, and Computer-Mediated Communications. Santa Monica: RAND Corporation.

Walther, J. B., Loh, T. and Granka, L. (2005): Let me count the ways: the interchange of verbal and nonverbal cues in computer-mediated and face-to-face affinity. Journal of Language and Social Psychology 24 (1): 36-65.

Weisband, S. P. (1992): Group discussion and first advocacy effects in computer-mediated and face-to-face decision making groups. Organizational Behavior and Human Decision Processes 53 (3): 352-380.

Wenger, E. (1998): Communities of Practice: Learning, Meaning, and Identity. Cambridge: Cambridge University Press.

Wickham, J. and Vecchi, A. (2008): Local firms and global reach: business air travel and the Irish software cluster. European Planning Studies 16: 693-710. 